\title{
Commentary
}

\section{Targeted Modulation of the Neuroinflammatory Response after Spinal Cord Injury}

\section{The Ongoing Quest for the "Holy Grail"}

\author{
Philip F. Stahel and Michael A. Flierl \\ From the Departments of Orthopaedic Surgery and Neurosurgery, \\ University of Colorado Denver, School of Medicine, Denver \\ Health Medical Center, Denver, Colorado
}

Healing of the injured spinal cord represents one of the remaining challenging frontiers in medicine. The posttraumatic neuroinflammatory response has been shown to contribute, at least in part, to the development of secondary neuronal cell death. ${ }^{1}$ Research strategies to prevent these pathological sequelae after spinal cord injury $(\mathrm{SCl})$ have largely failed in translation from the "bench to beside." ${ }^{2}$ A classic example related to our lack of understanding the basic immunological mechanisms that lead to delayed neuronal cell death is the failure to administer high-dose methylprednisolone to improve neurological outcome after $\mathrm{SCl} .{ }^{3}$ While considered a standard of care incorporated in clinical guidelines for many years, based on promising data from the NASCIS trials, high-dose steroids recently were recognized to be harmful, rather than beneficial, in the management of acute $\mathrm{SCl}$, and their application in the field of neurotrauma is now considered obsolete. ${ }^{4-6}$

Current research strategies in neurotrauma are therefore aimed at targeting more specific pathways of inflammation, such as the pharmacological inhibition of the complement cascade, which represents the major effector arm of the innate immune system. ${ }^{7}$ Interestingly, the first studies investigating complement activation in patients with $\mathrm{SCl}$ were published more than three decades ago. In 1980, Rebhuhn and Botvin ${ }^{8}$ showed that about two-thirds of all patients with $\mathrm{SCl}$ had elevated complement levels, and the authors postulated that complement activation may propagate a "self-feeding" immunological response responsible for the failure of regeneration of the injured spinal cord. The recent availability of higher quality complement reagents, including genetically engineered mice and tissue-targeted chimeric complement inhibitors, currently allows for the more detailed elucidation of specific pathways of complement activation involved in the pathophysiology of neuroinflammation after $\mathrm{SCl}^{7,9}$ (Figure 1).

The recent study by Qiao and colleagues ${ }^{10}$ published in this issue of The American Journal of Pathology was designed to analyze the role of the alternative activation pathway (factor B) and terminal lytic pathway (C5b-9) in contributing to the secondary neuropathological sequelae after traumatic SCl in adult C57BL/6 mice. ${ }^{10}$ In the first part of the study, a traumatic spinal cord contusion was applied to mice with a genetic deficiency for factor B $\left(\mathrm{fB}^{-1-}\right)$. These mice therefore lacked a functional alternative pathway of complement activation. ${ }^{11}$ Impressively, $\mathrm{fB}^{-1-}$ mice showed significantly improved locomotor function scores for up to 21 days after trauma, compared to wild-type controls. The neurological improvement was substantiated by significantly reduced neutrophil infiltration, complement deposition, and tissue damage in the injured spinal cord of $\mathrm{fB}^{-1-}$ mice, compared to that of wild-type littermates. These data imply a crucial role of complement activation, via the alternative pathway, in the development of posttraumatic neuroinflammation and propagation of delayed neuronal injury. In the second part of the study, these positive insights derived from gene knockout mice were translated to a pharmacological approach using a neutralizing monoclonal anti-factor B antibody (mAb1379), which is a potent inhibitor of the alternative complement activation pathway. ${ }^{12-13}$ Using a clinically relevant paradigm of systemic (intravenous) compound administration at 1 and 12 hours after trauma,

Accepted for publication May 3, 2010.

CME Disclosure: None of the authors disclosed any relevant financial relationships.

Address reprint requests to Philip F. Stahel, M.D., F.A.C.S., Department of Orthopaedic Surgery and Department of Neurosurgery, University of Colorado Denver, School of Medicine Denver Health Medical Center, 777 Bannock Street, Denver, CO 80204. E-mail: philip.stahel@dhha.org. 


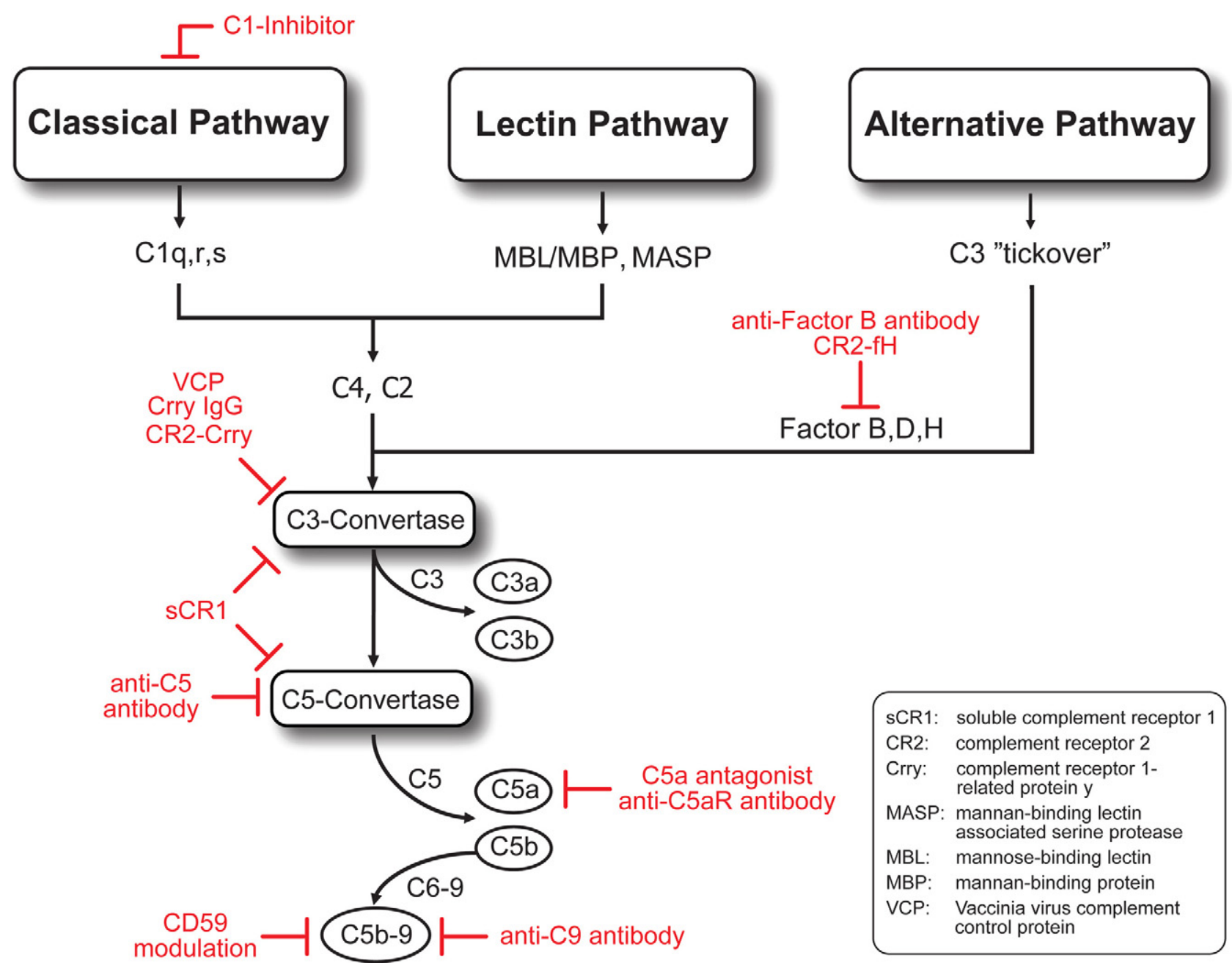

Figure 1. Simplified depiction of the three traditional complement activation pathways and the potential pharmacological interventions designed to ameliorate the extent of neuroinflammation and neuropathology after spinal cord injury. See text for details.

the authors were able to replicate the neuroprotective effects seen in $\mathrm{fB}^{-1-}$ mice, to the pharmacological mAb1379-treatment model in wild-type mice, using vehicle-injected animals as appropriate controls. Finally, the third part of the study was designed to determine the role of the membrane attack complex (C5b-9), as the terminal downstream event of complement activation, in the neuropathophysiology after $\mathrm{SCl}$. For this purpose, mice lacking the gene for the membrane-bound complement regulatory molecule CD59a (CD59a ${ }^{-1-}$ ) were subjected to traumatic spinal cord injury and analyzed by the same outcome parameters as for the $\mathrm{fB}^{-1-}$ mice. One of the putative mechanisms of complement-mediated neuronal death after spinal cord injury is represented by posttraumatic activation of phosphatidyl inositol-specific phospholipase C (PI-PLC), which renders neurons vulnerable to membrane attack complex-mediated lysis by shedding of the glycosyl phosphatidyl inositol-anchored glycoprotein CD59a from neuronal membranes. ${ }^{14-15}$ In contrast with data from $\mathrm{fB}^{-1-}$ mice and mAb1379-treated animals, CD59a ${ }^{-1-}$ mice showed a significant deterioration of neurological scores from 11 to 21 days after SCI, compared to wild-type littermates. In addition, deposition of complement C9, as a surrogate marker for the membrane attack complex (C5b-9), was significantly increased in the spinal cord of CD59a ${ }^{-1-}$ mice and associated with exacerbated tissue damage and local neutrophil infiltration. ${ }^{10}$

The exact cellular and molecular mechanisms of complement-mediated neuropathology after spinal cord injury remain far from fully understood. The present study ${ }^{10}$ sheds further light toward our understanding of the immunological pathophysiology of $\mathrm{SCl}$, as it offers novel insights into the impact of the different complement activation pathways (classical, alternative, lectin, and terminal pathway) and their involvement in posttraumatic neuroinflammation and neurodegeneration ${ }^{16-17}$ (Figure 1).

Recent experimental studies have provided initial evidence of involvement of the classical pathway of complement activation in the pathogenesis of neuronal tissue damage and adverse neurological outcome after SCl. ${ }^{18}$ In contrast, data from multiple studies on inflammatory conditions in and outside the CNS have revealed that the selective inhibition of the alternative complement pathway may represent a promising new immunomodulatory approach for multiple neuroinflammatory disor- 
ders. ${ }^{7,11,13,19-21}$ The current experimental study ${ }^{10}$ implies that the therapeutic inhibition of the alternative pathway (factor B) during a clinically relevant time window within 1 to 12 hours after trauma may represent a promising new avenue in the search for a pharmacological remedy to host-mediated progressive inflammation and neurodegeneration within the injured spinal cord. In this regard, it is notable that the monoclonal anti-factor B antibody used in the present study has cross-reactivity across species and was originally designed as an anti-human antibody. ${ }^{12-13}$ Thus, this specific compound has potential for promising "bench-to-bedside" translation in the future. Similarly, the therapeutic blockade of membrane attack complex assembly, by the use of anti-C9 antibodies, or stimulation/up-regulation of CD59 expression (eg, through gene therapy), may represent a new strategy to avoid "innocent bystander" complement-mediated neuronal lysis after spinal cord injury.

Future experimental studies must be designed to titrate the optimal dosage, time window of administration, and time intervals for repeated injections of these new generation complement inhibitory and regulatory molecules. One shortcoming of these therapeutic approaches is the potential for a limited extent of complement inhibition related to the half-life of these compounds and peak concentration at the site of the injured tissue. In this regard, repeated injections at closer time intervals and the use of newly available chimeric compounds consisting of complement inhibitors fused to complement receptors that bind at the site of complement activation, such as CR2-factor $\mathrm{H}$ and CR2-Crry molecules, ${ }^{9,22}$ may represent the future "golden bullet" for amelioration of complement-mediated exacerbation of SCl.

\section{References}

1. Chan CC: Inflammation: beneficial or detrimental after spinal cord injury? Recent Pat CNS Drug Discov 2008, 3:189-199

2. Buchli AD, Rouiller E, Mueller R, Dietz V, Schwab ME: Repair of the injured spinal cord: a joint approach of basic and clinical research. Neurodegen Dis 2007, 4:51-56

3. Hurlbert RJ: Methylprednisolone for acute spinal cord injury: an inappropriate standard of care. J Neurosurg 2000, 93:1-7

4. Sauerland S, Maegele M: A CRASH landing in severe head injury. Lancet 2004, 364:1291-1292

5. Kortbeek JB, Al Turki SA, Ali J, Antoine JA, Bouillon B, Brasel K, Brenneman F, Brink PR, Brohi K, Burris D, Burton RA, Chapleau W, Cioffi W, Collet e Silva Fde S, Cooper A, Cortes JA, Eskesen V, Fildes J, Gautam S, Gruen RL, Gross R, Hansen KS, Henny W, Hollands MJ, Hunt RC, Jover Navalon JM, Kaufmann CR, Knudson P, Koestner A, Kosir R, Larsen CF, Livaudais W, Luchette F, Mao P, McVicker JH, Meredith JW, Mock C, Mori ND, Morrow C, Parks SN, Pereira PM, Pogetti RS, Ravn J, Rhee P, Salomone JP, Schipper IB, Schoettker P, Schreiber MA, Smith RS, Svendsen LB, Taha W, van Wijngaarden-
Stephens M, Varga E, Voiglio EJ, Williams D, Winchell RJ, Winter R. Advanced trauma life support, edition 8: the evidence for change. J Trauma 2008, 64:1638-1650

6. Hurlbert RJ, Hamilton MG: Methylprednisolone for acute spinal cord injury: 5-year practice reversal. Can J Neurol Sci 2008, 35:41-45

7. Stahel PF, Barnum SR: The role of the complement system in CNS inflammatory diseases. Expert Rev Clin Immunol 2006, 2:445-456

8. Rebhuhn J, Botvin J: Complement elevation in spinal cord injury. Ann Allergy 1980, 44:287-288

9. Qiao F, Atkinson C, Song H, Pannu R, Singh I, Tomlinson S: Complement plays an important role in spinal cord injury and represents a therapeutic target for improving recovery following trauma. Am J Pathol 2006, 169:1039-1047

10. Qiao F, Atkinson C, Shunmugavel A, Morgan BP, Song H, Tomlinson $\mathrm{S}$ : The alternative and terminal pathways of complement mediate post-traumatic spinal cord inflammation and injury. Am J Pathol 2010, 177:3061-3070

11. Leinhase I, Holers VM, Thurman JM, Harhausen D, Schmidt OI, Pietzcker M, Taha ME, Rittirsch D, Huber-Lang M, Smith WR, Ward PA, Stahel PF: Reduced neuronal cell death after experimental brain injury in mice lacking a functional alternative pathway of complement activation. BMC Neurosci 2006, 7:55

12. Thurman JM, Kraus DM, Girardi G, Hourcade D, Kang HJ, Royer PA, Mitchell LM, Giclas PC, Salmon J, Gilkeson G, Holers VM: A novel inhibitor of the alternative complement pathway prevents antiphospholipid antibody-induced pregnancy loss in mice. Mol Immunol 2005, 42:87-97

13. Leinhase I, Rozanski M, Harhausen D, Thurman JM, Schmidt OI, Hossini AM, Taha ME, Rittirsch D, Ward PA, Holers VM, Ertel W, Stahel PF: Inhibition of the alternative complement activation pathway in traumatic brain injury by a monoclonal anti-factor B antibody: a randomized placebo-controlled study in mice. J Neuroinflammation 2007, 4:13

14. Stahel PF, Morganti-Kossmann MC, Kossmann T: The role of the complement system in traumatic brain injury. Brain Res Rev 1998 , 27:243-256

15. Morgan BP: Regulation of the complement membrane attack pathway. Crit Rev Immunol 1999, 19:173-198

16. Anderson AJ, Robert S, Huang W, Young W, Cotman CW: Activation of complement pathways after contusion-induced spinal cord injury. J Neurotrauma 2004, 21:1831-1846

17. Reynolds DN, Smith SA, Zhang YP, Mengsheng Q, Lahiri DK, Morassutti DJ, Shields CB, Kotwal GJ: Vaccinia virus complement control protein reduces inflammation and improves spinal cord integrity following spinal cord injury. Ann NY Acad Sci 2004, 1035:165-178

18. Galvan MD, Luchetti S, Burgos AM, Nguyen HX, Hooshmand MJ, Hamers FP, Anderson AJ: Deficiency in complement C1q improves histological and functional locomotor outcome after spinal cord injury. J Neurosci 2008, 28:13876-13888

19. Holers VM, Thurman JM: The alternative pathway of complement in disease: opportunities for therapeutic targeting. Mol Immunol 2004 , 41:147-152

20. Thurman JM, Holers VM: The central role of the alternative complement pathway in human disease. J Immunol 2006, 176:1305-1310

21. Banda NK, Thurman JM, Kraus D, Wood A, Carroll MC, Arend WP, Holers VM: Alternative complement pathway activation is essential for inflammation and joint destruction in the passive transfer model of collagen-induced arthritis. J Immunol 2006, 177:1904-1912

22. Banda NK, Levitt B, Glogowska MJ, Thurman JM, Takahashi K, Stahl GL, Tomlinson S, Arend WP, Holers VM: Targeted inhibition of the complement alternative pathway with complement receptor 2 and factor $\mathrm{H}$ attenuates collagen antibody-induced arthritis in mice. $\mathrm{J}$ Immunol 2009, 183:5928-5937 